\title{
Um Relato de Experiências de Estagiários da Licenciatura em Computação com o Ensino de Computação para Crianças
}

Pasqueline Dantas Scaico

UFPB - Rio Tinto, PB - Brasil, E-mail: pasqueline@dce.ufpb.br

Mychelline Souto Henrique

UFPB - Rio Tinto, PB - Brasil, E-mail: mychelline.henrique @dce.ufpb.br

Felipe Oliveira Miranda Cunha

UFPB - Rio Tinto, PB - Brasil, E-mail: felipe.cunha@dce.ufpb.br

Yugo Mangueira de Alencar

UFPB - Rio Tinto, PB - Brasil, E-mail: yugo.alencar@ dce.ufpb.br

Resumo: Este artigo relata uma experiência de estagiários da Licenciatura em Ciência da Computação com atividades que estimularam o pensamento computacional em turmas do ensino Fundamental. Diferente de outros trabalhos, os estagiários analisaram pontos falhos em uma atividade que se propõem a trabalhar o tema "Representação da Informação" e a modificaram, assim melhorando-a. Também se avaliou como diferentes turmas receberam os mesmos estímulos, tendo sido possível entender a partir de que ano escolar as crianças estavam aptas a receber as informações sobre aquele tema.

Palavras-chave: Computação desplugada. Educação básica. Licenciatura em Computação.

\section{Report of Experience of Trainees in Degree in Computing with Computer Science for Children}

\begin{abstract}
This work describes an experience of Computer Science students with activities that stimulated the computational thinking in elementary school classrooms. We have performed an analysis of the weak points in an activity intended to explore the theme "Information Representation". Besides, we have also evaluated how different groups received the same stimuli on this subject. This evaluation allowed the understanding of the ideal level for introducing to the children information about that theme.
\end{abstract}

Key words: Unplugged computing. Basic education. Degree in Computing. 


\section{Introdução}

A sociedade contemporânea vive mudanças de conceitos, valores e tecnologias. Devido ao ciclo natural do homem em procurar descobrir e aprender coisas novas, viver nessa sociedade requer apropriar-se de saberes e raciocínios específicos. Nessa perspectiva, diversos países estão buscando o acesso ao conhecimento com o uso de novas tecnologias. Esta oferta tem sido muitas vezes experimentada por meio da informatização das escolas. Além do que, percebe-se um progresso em relação a isso, emergindo desse contexto iniciativas que buscam introduzir tecnologias no processo educativo e adaptando o uso da Computação, enquanto ciência, ao currículo escolar.

Dentre os progressos resultantes da inclusão do ensino de tecnologias no currículo escolar, destaca-se o currículo em ciência da computação na educação secundária em Israel (Gal-Ezer 1999), no Canadá (MEO 2008) e nos Estados Unidos, onde mais especificamente o modelo de currículo chama atenção para conteúdos que permitem o alcance da chamada Educação Imperativa, na qual mais importante do que aprender temas ligados às tecnologias, está a capacidade de desenvolver o pensamento computacional (CSTA 2005).

A discussão sobre produzir um currículo contendo conteúdos da Ciência da Computação na educação básica reflete um avanço no sistema educacional, já que assim, se estabeleceria um espaço para o desenvolvimento de novas habilidades, que serão demandas para os bons profissionais em um futuro muito próximo, a exemplo da capacidade de resolver problemas, de simplificar e interpretar, de liderar, trabalhar em equipe e da fluência no uso de tecnologias para quaisquer áreas do conhecimento.

Pode-se dizer que, no Brasil, as escolas ainda estão em um estágio inicial desse processo porque ensinar computação para crianças e adolescentes se confunde, por vezes, com as aulas de informática, que se referem à instruções voltadas para capacitar para o manuseio de aplicativos de escritório, a edição gráfica e de ferramentas de gerenciamento de conteúdo web. Embora muitas escolas brasileiras apresentem recursos tecnológicos que superam a realidade de outros países, com salas de aulas e laboratórios de informática bem equipados, o modelo mental que os alunos desenvolvem sobre os sistemas computacionais ainda se molda a uma perspectiva de capacitar usuários de aplicativos.

É preciso desenvolver uma visão ampla sobre a Computação na escola, de maneira que ela não seja apenas utilizada para entretenimento ou como auxílio ao ensino de outras disciplinas para "fixar a atenção" dos alunos. Mas, principalmente, como um mecanismo capaz de ampliar a visão do estudante para a concepção e a implementação de software e hardware, através do ensino de técnicas indicadas para a resolução de problemas, o estudo de programação e o raciocínio lógico.

O entendimento sobre os princípios da construção de soluções computacionais, suas aplicações e seu impacto na sociedade é primordial para a formação do cidadão contemporâneo, capaz não apenas de consumir a informação, mas de ser um agente na produção do conhecimento. Diversos trabalhos, entre eles os de Garcia et al. (Garcia et al. 2008) e Barros et al (Barros et al. 2009) demonstram a tentativa de desenvolver a competência de desenvolver programas com alunos do ensino médio.

Esse trabalho registra uma prática docente no ensino de princípios da Ciência da Computação em uma escola de ensino Fundamental na cidade de João Pessoa, Paraíba. A proposta para o trabalho surgiu a partir dos estudos realizados por estudantes do curso de Licenciatura em Ciência da Computação da Universidade Federal da Paraíba, Campus IV, na disciplina Estágio Curricular Supervisionado. Durante as discussões 
sobre como a Computação vem sendo empregada em currículos escolares de diversos países e de uma análise sobre o ensino de informática nas escolas brasileiras, principalmente na cidade em questão, percebeu-se que nunca houvera existido qualquer iniciativa para inserir este tema nas escolas locais.

A partir das discussões geradas em sala de aula e da observação do campo de estágio, foi proposto um plano de trabalho para o ensino dos princípios da computação com alunos do $5^{\circ}$ ao $9^{\circ}$ ano. Este plano teve como objetivo experimentar um método para o ensino dos fundamentos da computação que dispensa o uso de computadores e qualquer meio digital em sua aplicação, e que é baseado no livro "Ciência da Computação Desplugada" (do inglês, Computer Science Unplugged) (CC 2005) e de avaliar como turmas de diferentes anos do ensino Fundamental se comportariam com os estímulos ao pensamento computacional.

Apesar de reconhecer a qualidade do livro, os alunos perceberam que ajustes em algumas atividades propostas poderiam melhorar a didática das atividades, como é o da atividade "Contando os pontos".

Este trabalho está organizado da seguinte maneira: a Seção 2 apresenta o ambiente do estágio. Na Seção 3 está descrita a natureza da atividade realizada na escola, assim como, os detalhes da atividade e a impressão que os estagiários tiveram após a sua primeira aplicação. A Subseção 3.2 mostra os ajustes realizados no material didático utilizado para tornar a atividade mais didática para os alunos. Na Subseção 3.3, é mostrado, como em um segundo momento, a atividade passou a ser conduzida. A Seção 4 descreve uma avaliação simples, que mostrou o desempenho de alunos em faixa etária diferentes. Na Seção 5 analisam-se, rapidamente, as propostas do currículo americano em relação à proposta executada pela escola atualmente. E, por fim, a Seção 6 traz as considerações finais.

\section{Contextualização}

O estágio aconteceu na escola privada de ensino fundamental Centro de Ensino Decisão, localizada no bairro de Mangabeira na cidade de João Pessoa, Paraíba. A escola tem em seu currículo aulas de informática como um componente não obrigatório. A professora de informática da escola não possuía formação em licenciatura na área, mas apenas conhecimento técnico para lecionar a referida disciplina.

O material utilizado na escola é um kit que apresenta um livro para cada ano escolar, no qual conteúdos específicos de informática são abordados, a exemplo de conceitos relacionados ao sistema operacional, busca na internet, uso básico de uma ferramenta de edição de textos, criação de vídeos, planilhas eletrônicas e slides.

$\mathrm{O}$ contato dos estagiários com as aulas de informática aconteceu em um primeiro momento através do acompanhamento das aulas em laboratório, com a observação direta. A partir disso, detectou-se que as aulas não fluíam a contento com os alunos dos anos finais do Fundamental. Os alunos do $9^{\circ}$ ano, por acumularem conhecimentos sobre tecnologia no dia a dia apresentavam grande resistência às aulas de informática, consideradas, por eles, monótonas. Após o período de observação, propôs-se à escola que um novo conteúdo, que tratava de aspectos da Computação, fosse apresentado a algumas turmas, as quais estavam distribuídas em diferentes anos escolares.

\section{A natureza da atividade proposta}


As atividades desenvolvidas por Tim Bell, Lan H. Witten e Mike Fellows contidas no livro "Computer Science Unplugged" tem o intuito de ensinar fundamentos sobre a Ciência da Computação sem o uso do computador (Bell et al., 2007). Este método de ensino é interessante por criar situações que exploram questões relacionadas ao trabalho em equipe, a resolução de problemas e a criatividade.

Com as atividades propostas é possível praticar o Pensamento Computacional, que se refere ao uso de técnicas utilizadas na Computação para a resolução de problemas, como é o caso da abstração de conceitos e divisão e conquista. Os estudantes aprendem como os computadores fazem para resolver problemas e aplicam técnicas, através de uma abordagem problematizadora e orientada a desafios, para resolver situações do cotidiano.

A atividade escolhida para esta experiência trata do tema "Representação da Informação", que discute a linguagem utilizada pelo computador para processar e entender textos, imagens, sons e vídeos. Para explicar a linguagem binária foi dito que o computador entendia apenas zeros e uns, e que sequências poderiam ser formadas a partir desses dois algarismos. As atividades foram executadas por estagiários, mas acompanhada pela professora de Informática da escola.

\subsection{A primeira execução da atividade Contando os Pontos}

Uma turma do $4^{\circ}, 5^{\circ}$ e $9^{\circ}$ ano foi utilizada neste primeiro momento. A atividade original propunha o uso de cartões contendo pontos para representar os bits e os seus valores. Foi dito que, ao ligar um bit, os valores relacionados à sua posição eram utilizados para representar os números no sistema decimal. A Figura 1 ilustra os cartões propostos. Cada cartão representa um bit que possui um valor próprio, o primeiro bit (da direita para a esquerda) tem valor um, o segundo valor dois, o terceiro quatro e assim sucessivamente, sendo que o próximo bit terá sempre o dobro do seu antecessor.
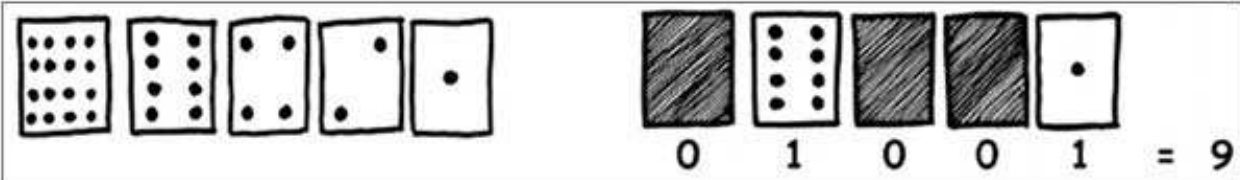

Figura 1 - Cartões da atividade Contando os pontos

Ao executar a atividade, percebeu-se que os alunos do $4^{\circ}$ e $5^{\circ}$ ano não conseguiram abstrair o significado do zero e do um para o computador. Mesmo após explicar a relação de um número no sistema binário com um número no sistema decimal, mostrando que a posição do bit é quem definiria o seu valor em decimal, percebeu-se que ao virar o cartão (movimento que representava o bit sendo ligado) era apresentado um conjunto de pontos.

Ao fazer a leitura dos cartões de pontos, as crianças associavam inconscientemente o valor numérico do cartão. Sendo assim, por mais que os pontos estivessem sendo utilizados para a analogia, o significado que estava sendo construído com os cartões remetia a um numeral que não existia no sistema binário, como é o caso do numeral oito, representado pelo bit 4 na Figura 1. Isso causou confusão para as crianças entenderem a existência de apenas zeros e uns no sistema binário e o processo de conversão entre os sistemas.

\subsection{A alteração da atividade Contando os pontos}


Novos cartões foram confeccionados e neles foram impressos em um lado uma lâmpada acesa e no outro uma lâmpada apagada, conforme mostra a Figura 2, abaixo. A associação que se criou entre o conceito da lâmpada com o conceito do bit foi que, se a lâmpada estivesse acessa o bit estaria ligado (sendo chamado de um). Se a lâmpada estivesse apagada o bit estaria desligado (sendo chamado de zero).

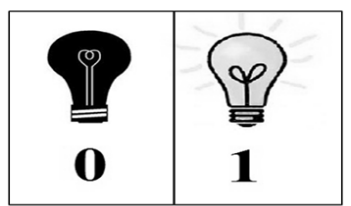

Figura 2 - Novos cartões para a atividade Contando os pontos

Antes de apresentar esta analogia os estagiários acrescentaram a informação de que o computador funcionava através de eletricidade, assim como outros equipamentos eletrônicos que eles conheciam. Assim, um bit, quando ligado, significava a presença de um estímulo elétrico nas partes internas do computador.

Para a explicação desses conceitos relativamente complexos foi acrescentado o uso de representações mais significativas para as crianças, ou seja, o uso de diferentes metáforas. Uma delas incluiu a discussão do funcionamento de alguns eletrodomésticos, que eles conheciam. Os cartões produzidos para esta atividade receberam em suas faces imagens coloridas das lâmpadas.

\subsection{A segunda execução da atividade Contando os pontos}

A segunda aplicação desta atividade passou por novas turmas dos mesmos anos letivos. Após a explicação inicial foram escolhidos cinco voluntários. A cada um deles foi entregue um cartão, que representava um bit. As crianças foram dispostas lado a lado e acima de cada uma delas foi posicionado o valor em decimal de cada um dos bits. Usando os cinco bits é possível representar no máximo o número decimal 31, isso porque é necessário somar todas as posições representadas em decimal, são elas: 1, 2, 4, 8 e 16. Caso seja necessário representar um número maior que 31, é necessário incluir outro bit. A Figura 3 abaixo mostra o momento da aplicação com uma das turmas.

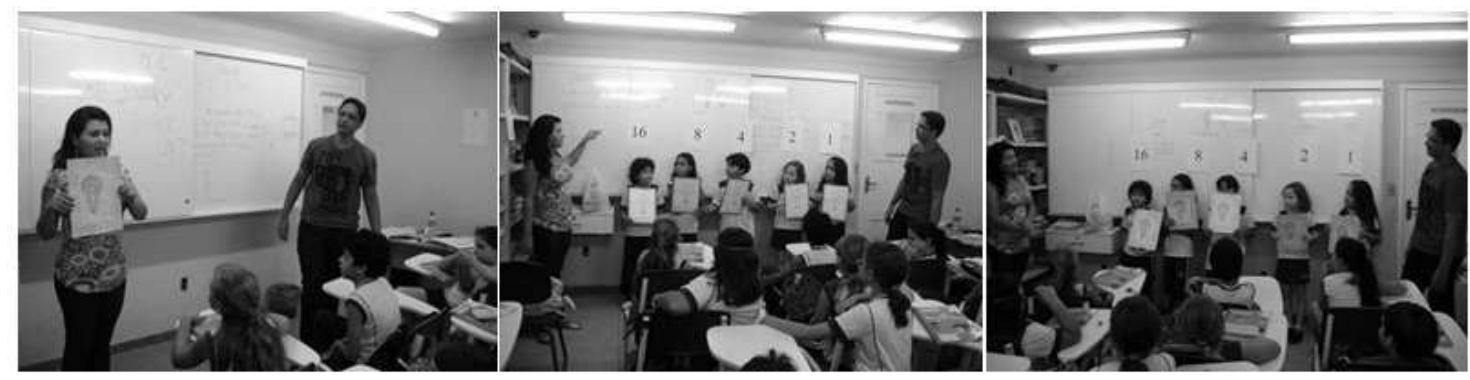

Figura 3 - Aplicação da atividade com os novos cartões

Durante a atividade, questionamentos simples foram feitos pelos estagiários para estimular os alunos a raciocinarem sobre a representação de números no sistema decimal e no sistema binário, e sobre a conversão entre os sistemas. Perguntou-se em um determinado momento, que número decimal estava sendo representado quando todas as lâmpadas estavam ligadas. A maioria dos alunos compreendeu rapidamente a conversão entre os dois sistemas de numeração (que estava ocorrendo a partir da soma dos valores dos bits). Outras perguntas utilizaram números aleatórios em um intervalo 
de zero a trinta e um. Neste momento percebeu-se que os alunos não estavam utilizando a lógica correta para identificar os valores em decimal.

Os estagiários explicaram que eles deveriam "ligar" os bits, cuja soma dos valores não ultrapassasse o valor em decimal, até que se chegasse ao número desejado. Na sequência pôde-se perceber que os alunos entenderam a instrução. Para aumentar o nível de dificuldade, perguntou-se como seria a representação do número 35 em binário. Nas turmas de $9^{\circ}$ ano foram utilizados os mesmos procedimentos, atribuindo agora oito bits. A definição de byte e da codificação ASCII foi introduzida para estas turmas.

\section{Avaliação}

A atividade Contando os Pontos foi aplicada em todos os anos escolares do Fundamental. Entretanto, apenas com as turmas do $5^{\circ}$ e do $9^{\circ}$ ano foram executados testes após as aplicações. Esses testes foram realizados com o objetivo mensurar a dificuldade que os alunos, em faixas etárias diferentes, tiveram ao receber a atividade. Para a avaliação os estagiários dispuseram diversos números decimais que deveriam ser convertidos em sequências binárias correspondentes. Para agrupar as respostas consideraram-se quatro possibilidades: i. quantidade de alunos que acertou todas as questões, ii. que acertou metade, iii. menos da metade e iv. errou todas as questões.

$\mathrm{Na}$ turma do $5^{\circ}$ ano havia 24 estudantes, de faixa etária entre 7 a 9 anos. Estavam presentes 8 meninos e 16 meninas. Já na turma do $9^{\circ}$ ano havia 26 alunos, sendo 10 meninos e 16 meninas, na faixa etária de 13 a 16 anos. Observando a Tabela 1 percebe-se que a turma do $5^{\circ}$ ano obteve, no geral, um desempenho superior à turma do $9^{\circ}$ ano. O que sugere que a atividade "Contando os pontos" é adequada para estudantes nessa faixa etária.

Vale ressaltar também o bom desempenho que as meninas das duas turmas alcançaram. Vê-se ainda que, $62,50 \%$ das meninas do $5^{\circ}$ ano acertaram todas as questões, sendo este um resultado melhor em comparação às meninas do $9^{\circ}$ ano.

Tabela 1 - Resultados de acertos e erros nas questões propostas

\begin{tabular}{|l|c|c|c|c|}
\hline \multirow{2}{*}{ Critérios } & \multicolumn{2}{|c|}{$\mathbf{5}^{\circ}$ ANO } & \multicolumn{2}{c|}{ 9 $^{\circ}$ ANO } \\
\cline { 2 - 5 } & Meninos & Meninas & Meninos & Meninas \\
\hline $100 \%$ de acertos & $25 \%$ & $62,5 \%$ & $20 \%$ & $18,75 \%$ \\
\hline $50 \%$ de acertos & $12,5 \%$ & $18,75 \%$ & $50 \%$ & 0 \\
\hline Menos de $50 \%$ de acertos & $37,5 \%$ & $18,75 \%$ & $20 \%$ & $81,75 \%$ \\
\hline $0 \%$ de acertos & $25 \%$ & 0 & $10 \%$ & 0 \\
\hline
\end{tabular}

Na próxima seção são correlacionadas algumas características do currículo para o ensino de Computação K-12 (modelo americano) com os conteúdos propostos pelo currículo para o ensino de Informática adotado pela escola em que o projeto foi realizado.

\section{Correspondência do currículo $K-12$ e o kit didático utilizado na escola}

O sistema educacional norte americano possui um currículo próprio para ensinar Computação, denominado Currículo K-12. Ele abrange os graus que vão do jardim de infância (K) ao ensino médio (grau 12). A proposta desse currículo tem como meta 
preparar os alunos para entender a natureza da Ciência da Computação, incluindo seus princípios, e desenvolver as habilidades necessárias para resolver problemas cotidianos, o que também é útil para o aprofundamento de assuntos na área de Computação. A introdução da Computação inicia-se com os alunos na faixa etária de oito anos, os quais começam a estudar conceitos básicos da computação.

As características da estrutura do currículo K-12 estão apresentadas na Tabela 2 e organizadas com relação aos conteúdos trabalhados em cada nível, as habilidades que se procura desenvolver, além de atividades desplugadas sugeridas para cada nível. Na Tabela 2 também estão descritos os conteúdos abordados no kit didático usado pela escola, de acordo com o ano letivo.

O kit didático utilizado na escola é composto de livros que abrangem atividades para a educação infantil (crianças entre 4 e 6 anos), o ensino fundamental (alunos entre 7 e 14 anos) e o ensino médio, que abrange os adolescentes a partir na faixa etária dos 15 aos 17 anos.

Ao analisar as propostas do K-12 e do kit da escola, percebe-se que há poucos conteúdos compatíveis para os diferentes níveis de instrução. E, também que os conteúdos abordados no kit repetem assuntos que foram abordados em anos letivos anteriores, ocorrendo assim uma estagnação nos assuntos de informática. Este é o caso dos conteúdos que exploram a produção de vídeo, Web e link e uso de aplicativos de escritório.

A partir desta análise, pode-se entender que o currículo k-12 surge com uma proposta mais eficiente e completa no que diz respeito à abrangência de conceitos da Ciência da Computação. 
Tabela 2 - Conteúdos do Currículo K-12 e do kit utilizado na escola

\begin{tabular}{|c|c|c|c|c|c|}
\hline \multicolumn{6}{|c|}{ Currículo K-12 } \\
\hline & Nível I & Nível II & Nível III & \multicolumn{2}{|c|}{ Nível IV } \\
\hline \multirow[b]{2}{*}{$\frac{\stackrel{0}{0}}{\stackrel{0}{\tilde{\theta}}}$} & 6 a 8 anos & 9 anos & 10 anos & \multicolumn{2}{|c|}{11 anos } \\
\hline & $\begin{array}{l}\text { Apresentação de } \\
\text { ferramentas de } \\
\text { produtividade } \\
\text { (editores de texto, } \\
\text { apresentação) } \\
\text { Introdução ao } \\
\text { pensamento } \\
\text { algoritmo } \\
\text { Noções de hardware } \\
\text { e software }\end{array}$ & $\begin{array}{l}\text { Números binários } \\
\text { Lógica matemática } \\
\text { Desenvolvimento } \\
\text { de programas } \\
\text { simples } \\
\text { Noções de redes de } \\
\text { computadores }\end{array}$ & $\begin{array}{l}\text { Design de } \\
\text { usabilidade e } \\
\text { interface } \\
\text { Estruturas de dados } \\
\text { Introdução à } \\
\text { Linguagens de } \\
\text { programação e aos } \\
\text { conceito de tradutor } \\
\text { e compilador }\end{array}$ & \multicolumn{2}{|c|}{$\begin{array}{l}\text { Tecnologias de redes } \\
\text { Programação web } \\
\text { Cursos de certificação } \\
\text { avançados }\end{array}$} \\
\hline 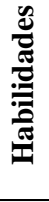 & Raciocínio lógico & $\begin{array}{l}\text { Lógica matemática } \\
\text { e de programação }\end{array}$ & $\begin{array}{l}\text { Resolução de } \\
\text { problemas } \\
\text { Interpretação e } \\
\text { trabalho em equipe }\end{array}$ & \multicolumn{2}{|c|}{$\begin{array}{l}\text { Autonomia, maturidade para } \\
\text { estudos avançados }\end{array}$} \\
\hline \multicolumn{6}{|c|}{ Kit utilizado na escola } \\
\hline & $5^{\circ}$ ANO & $6^{\circ}$ ANO & $7^{\circ}$ ANO & $8^{\circ}$ ANO & $9^{\circ}$ ANO \\
\hline \multirow[b]{2}{*}{$\frac{\mathscr{0}}{\stackrel{0}{0}}$} & 9 anos & 10 anos & 11 anos & 12 anos & 13 anos \\
\hline & $\begin{array}{l}\text { Aplicativos de } \\
\text { escritório } \\
\text { Editoração gráfica } \\
\text { Noções de Web, } \\
\text { páginas e hiperlinks } \\
\text { Pesquisa na Internet }\end{array}$ & $\begin{array}{l}\text { Aplicativos de } \\
\text { escritório } \\
\text { Noções de internet } \\
\text { Editoração gráfica- } \\
\text { criação de vídeos }\end{array}$ & $\begin{array}{l}\text { Noções de } \\
\text { armazenamento } \\
\text { Produção de } \\
\text { animações } \\
\text { Aplicativos de } \\
\text { escritório } \\
\text { Recursos } \\
\text { multimídia }\end{array}$ & $\begin{array}{l}\text { Produção de } \\
\text { materiais } \\
\text { instrucionais } \\
\text { Layout de } \\
\text { materiais } \\
\text { O computador } \\
\text { Noções de } \\
\text { programas }\end{array}$ & $\begin{array}{l}\text { Produção de } \\
\text { vídeo } \\
\text { Conceitos de } \\
\text { sites web } \\
\text { O } \\
\text { Processador }\end{array}$ \\
\hline
\end{tabular}

Entretanto, a avaliação realizada com a turma do $5^{\circ}$ ano mostrou que, após o ajuste na atividade "Contando os pontos", os alunos estão preparados cognitivamente para os estímulos propostos pelo pensamento computacional.

\section{Considerações finais}

A prática docente aqui relatada foi muito importante para iniciar um processo de amadurecimento e consolidação do curso de Licenciatura em Ciência da Computação da Universidade Federal da Paraíba. Até então, as experiências vivenciadas pelos estagiários nas escolas se restringiam ao suporte tecnológico como mediador das 
práticas dos professores de outras áreas do conhecimento. Assumir a regência de aulas de Computação, principalmente para alunos do nível Fundamental, foi o momento em que os estagiários puderam perceber a dimensão da sua formação.

Os estagiários puderam refletir sobre diversos aspectos do trabalho. Do ponto de vista pedagógico, analisaram como algumas atividades propostas no livro Computação Desplugada poderiam ser melhoradas para a realidade da escola. Também, ao realizar um estudo mais aprofundado de adequabilidade de uma atividade para uma série escolar puderam diagnosticar e tomar ações que favoreceram a aprendizagem dos alunos da escola.

Este trabalho abriu inúmeras possibilidades de melhoria na formação e atuação dos envolvidos com a Licenciatura em Computação, haja vista que, após este primeiro contato, um total de cem alunos foi incluído no projeto Computação Desplugada na escola em questão, que passou a ser desenvolvido em um modelo de gincana por outros estagiários. Um curso está sendo produzido para treinar alunos da escola que desejam participar da Olimpíada Brasileira de Informática.

Este trabalho foi pioneiro na cidade e, apesar de refletir um estudo pontual, traz uma contribuição importante que é a certeza da possibilidade de trabalhar o pensamento computacional nas escolas. Diversas discussões iniciaram para que os estagiários da Licenciatura pudessem perceber sua contribuição na construção de um modelo de educação mais alinhado às demandas do ensino de qualidade, já exigido por alguns exames nacionais, como é o caso do ENEM, que requer claramente a necessidade de o aluno estar preparado para a reflexão, a interdisciplinaridade e aplicação do conhecimento.

Em relação aos resultados para a escola, foi possível apontar a possibilidade de estabelecer indicadores que poderiam reforçar a deficiência dos alunos na aplicação de conhecimentos da Matemática. Percebeu-se que ao aplicar as atividades desplugadas, inúmeros conteúdos da matemática poderiam ser trabalhados nos diferentes anos escolares, a exemplo da potenciação, dos sistemas de numeração, operações aritméticas e lógicas, além das possibilidades de desenvolver em sala temas transversais como é o caso do uso de tecnologias e do estímulo ao desenvolvimento de habilidades, como a associação, o uso de metáforas e a abstração de conceitos. Algumas atividades desplugadas estão sendo estudadas para que sejam fonte de subsídio para a produção de sequências didáticas para as aulas de Matemática.

Finalmente, é desejo dos autores deste artigo que outros cursos de Licenciatura possam investir na formação plena de seus alunos através da captação de campos de estágio que realmente os façam perceber a grande missão que eles têm: que é a de criar, na medida do possível, nos espaços escolares a percepção da importância do licenciado em Computação e mais, de disseminar para a sociedade os benefícios da educação de uma área de conhecimento que ela ainda desconhece.

\section{Referências Bibliográficas}

BARROS, L.; RIBEIRO, S.P.S.; OEIRAS, J. Projeto de Extensão Universitária para apoio e realização da Olimpíada Brasileira de Informática em Escolas. In: XXIX Congresso da SBC - XVII WEI, 2009, Bento Gonçalves. Anais.

BELL, T.; WHITTEN, I.; FELLOWS, M. Computer Science Unplugged. Universidade de Canterbury, Nova Zelândia, 2007. 105 p. Disponível em: <http://csunplugged.org/> Acesso em: 12 Fev. 2012. 
COMPUTER SCIENCE TEACHER ASSOCIATION - CSTA. The New Educational Imperative: Improving High School Computer Science Education. Final Report of the CSTA, 2005. Curriculum Improvement Task Force. ACM - Association for Computing Machinery.

GAL-EZER, J. AND D. HAREL. Curriculum for a high school computer science curriculum, 1999. Computer Science Education 9(2).

GARCIA, R. E.; CORREIA, R. C. M.; SHIMABUKURO, M. H. Ensino de Lógica de Programação e Estruturas de Dados para Alunos do Ensino Médio, In: Anais do XXVIII WEI, CSBC'2008, Belém.

MINISTÉRIO DA EDUCAÇÃO DE ONTARIO - MEO. Currículo para o ensino de Ciência da Computação nas escolas, 2008. Disponível em: <www.edu.gov.on.ca〉. Acesso em: 12 Fev. de 2012>.

PEREIRA JÚNIOR, J.; RAPKIEWICZ, C.E.; DELGADO, C.; XEXEO, J.A.M. Ensino de Algoritmos e Programação: Uma Experiência no Nível Médio, In: XIII Workshop de Educação em Computação, WEI'2005, São Leopoldo. 